\title{
S100A8 facilitates cholangiocarcinoma metastasis via upregulation of VEGF through TLR4/NF-кB pathway activation
}

\author{
SHUGUANG PAN ${ }^{1 *}$, YING HU $^{2 *}$, MENGJIA HU $^{1}$, YANG XU $^{1}$, MO CHEN $^{1}$, \\ CHANGHONG DU ${ }^{1}$, JINCHI CUI ${ }^{3}$, PING ZHENG ${ }^{3}$, JIEJUAN LAI $^{3}$, YUJUN ZHANG ${ }^{3}$, \\ $\mathrm{JIE} \mathrm{BAI}^{3}$, PENG JIANG ${ }^{3}$, JIN ZHU ${ }^{3}, \mathrm{YU} \mathrm{HE}^{3}$ and JUNPING WANG ${ }^{1}$ \\ ${ }^{1}$ State Key Laboratory of Trauma, Burns and Combined Injury, Institute of Combined Injury, \\ Chongqing Engineering Research Centre for Nanomedicine, College of Preventive Medicine, \\ Third Military Medical University; ${ }^{2}$ Oncology Department, Southwest Hospital, \\ Third Military Medical University; ${ }^{3}$ Institute of Hepatobiliary Surgery, \\ Southwest Hospital, Third Military Medical University, Chongqing 400038, P.R. China
}

Received April 30, 2019; Accepted October 3, 2019

DOI: 10.3892/ijo.2019.4907

\begin{abstract}
A growing body of evidence indicates that S100 calcium-binding protein A8 (S100A8) is frequently overexpressed in malignant tumor tissues and regulates tumor progression; however, the role of S100A8 in cholangiocarcinoma (CCA) remains unclear. The present study demonstrated that the protein expression of S100A8 was significantly higher in pathological tissues compared with adjacent normal tissues from patients with CCA. In addition, S100A8 expression was significantly associated with differentiation, lymph node metastasis and poor prognosis in patients following surgical resection of CCA. Furthermore, both in vitro and in vivo experiments revealed that overexpression of S100A6 promoted, while S100A8 knockdown attenuated, the migration and metastasis of CCA cells. Of note, the present results indicated that S100A8 promoted the CCA tumor cell-induced migration of vascular endothelial cells. Finally, S100A8 was demonstrated to positively regulate the expression of vascular endothelial
\end{abstract}

Correspondence to: Professor Junping Wang, State Key Laboratory of Trauma, Burns and Combined Injury, Institute of Combined Injury, Chongqing Engineering Research Centre for Nanomedicine, College of Preventive Medicine, Third Military Medical University, 30 Gaotanyan Street, Chongqing 400038, P.R. China

E-mail: wangjunping@tmmu.edu.cn

Dr Yu He, Institute of Hepatobiliary Surgery, Southwest Hospital, Third Military Medical University, 30 Gaotanyan Street, Chongqing 400038, P.R. China

E-mail: heyu717@163.com

*Contributed equally

Key words: cholangiocarcinoma, metastasis, S100 calcium-binding protein $\mathrm{A} 8$, vascular endothelial growth factor, $\mathrm{NF}-\kappa \mathrm{B}$ pathway growth factor (VEGF) in CCA cells, which was mediated by activation of the Toll-like receptor 4 (TLR4)/NF- $\kappa \mathrm{B}$ pathway. In conclusion, the present study demonstrated that S100A8 had an important role in facilitating CCA cell migration and metastasis via upregulation of VEGF expression by activating the TLR4/NF- $\kappa \mathrm{B}$ pathway. These findings may provide a novel target for CCA treatment.

\section{Introduction}

Cholangiocarcinoma (CCA) is currently one of the most common malignant tumors in the biliary tract $(1,2)$. CCA is prone to invasion and metastasis into blood vessels and distant lymph nodes, thereby complicating clinical surgical treatment $(1,3)$. Tumor metastasis is the main cause of cancer-related death (4). Once a tumor metastasizes, the prognosis becomes extremely poor, despite the prominent advances that have been made in cancer treatment over the past few decades $(4,5)$. Tumor invasion and metastasis are complex biological processes involving multiple factors, during which tumor cells detach from the primary site and interact with the extracellular matrix, forming a migration channel for tumor cells $(4,6,7)$. Tumor cells then enter the peripheral blood vessels through the vascular basement membrane, leading to dissemination of the tumor cells in distant tissues, where they finally colonize and form metastatic foci $(8,9)$. However, the underlying molecular mechanisms have not been fully elucidated.

S100 calcium-binding protein A8 (S100A8), also known as myeloid-related protein 8 , is a calcium-binding protein recognized as an endogenous ligand of Toll-like receptor 4 (TLR4). S100A8 has been reported to be highly expressed in bone marrow-derived cells, such as neutrophils (10). In addition, S100A8 protein can be secreted in the form of heterodimers by necrotic cells and pathogen-associated molecular pattern-activated immune cells (10-12). Of note, S100A8 has been found to positively regulate the progression of malignant tumors and the dissemination of tumor cells $(13,14)$. 
Consistent with these findings, S100A8 protein is frequently overexpressed in a variety of tumors, such as lung cancer, colon cancer, gastric cancer, pancreatic cancer, and primary liver cancer $(4,10,15)$. However, whether S100A8 is expressed in CCA remains unclear.

Vascular endothelial growth factor (VEGF) is a protein that specifically affects endothelial cells $(16,17)$. The binding of VEGF to its receptor VEGFR, a tyrosine protein kinase, serves a crucial role in promoting endothelial cell proliferation, migration, budding, vascular growth and permeability enhancement (17-19). Blood vessels in tumors are known to be critical for malignant tumor growth, invasion and metastasis (20-22), and in most cancers, microvessel formation is a prognostic indicator of tumor metastasis, recurrence and survival $(20,23)$. Tumor remodeling and angiogenesis are complex processes that require activation of multiple vascular components: Endothelial cell division, vascular basement membrane degradation, peripheral extracellular matrix degradation and endothelial cell migration $(7,24)$. Previous studies have confirmed that VEGF is secreted by tumor cells and has a major regulatory role in angiogenesis in various types of cancer, by promoting the expansion of endothelial cells $(16,17)$; however, the exact role of VEGF in CCA is poorly understood.

The present study demonstrated that $\mathrm{S} 100 \mathrm{~A} 8$ protein expression was high in CCA tissues and significantly associated with malignant pathology, differentiation, lymph node metastasis and poor prognosis in patients with CCA. Further investigations revealed that $\mathrm{S} 100 \mathrm{~A} 8$ activated the TLR4/NF- $\mathrm{\kappa B}$ pathway to increase VEGF secretion and to thereby promote CCA invasion and metastasis. Collectively, the findings indicated that S100A8 may be a vital molecule in promoting CCA invasion and metastasis.

\section{Materials and methods}

CCA tissue specimens. Pathological specimens were obtained from 134 patients with hilar cholangiocarcinoma who underwent surgical treatment in the Department of Hepatobiliary Surgery at the Southwest Hospital Affiliated with the Third Military Medical University (Chongqing, China) from January 2010 to December 2015. All patients were re-examined using upper abdominal color Doppler ultrasound and computed tomography angiography (CTA) every three months after discharge. Overall survival was calculated from the date of surgery until the date of last contact. All neutrophil counts were derived from routine blood tests. The present study was approved by the Ethics Committee of the Third Military Medical University and followed the guidelines of the Declaration of Helsinki.

Animals. A total of 20 male BALB/c-nu mice (age, 4-6 weeks; weight, 18-22 g) were purchased from the Institute of Laboratory Animal Sciences of the Chinese Academy of Sciences. The mice were randomly divided into four groups and were housed under specific pathogen-free conditions (temperature, 24-26 ${ }^{\circ} \mathrm{C}$; humidity, 40-60\%; ventilation, 15 times/h; 12 -h light/dark cycle; free access to food and water). All animals received humane care according to the criteria outlined in the 'Guide for the Care and Use of Laboratory Animals'
(National Institutes of Health), and the animal experiment protocols were approved by the Institutional Animal Care and Use Committee of the Third Military Medical University. All mice were sacrificed via intraperitoneal injection of excessive sodium pentobarbital.

Cell culture. The human CCA cell lines RBE and HCCC-9810 and the human umbilical vein endothelial cell (HUVEC) line were obtained from the Cell Bank of Type Culture Collection of the Chinese Academy of Sciences. The cells were cultured in RPMI-1640 (Gibco; Thermo Fisher Scientific, Inc.) medium containing $10 \%$ fetal bovine serum (FBS; Zeta Life, Inc.) and maintained in a humidified incubator containing $5 \% \mathrm{CO}_{2}$ at $37^{\circ} \mathrm{C}$.

Reagents. The TLR4 inhibitor TAK242 (cat. no. HY-11109) and the NF- $\mathrm{KB}$ inhibitor ammonium pyrrolidinedithiocarbamate (PDTC; cat. no. HY-18738) were purchased from MedChemExpress. The TAK-242 (25) and PDTC (26) doses used in the present study were 20 and $40 \mu \mathrm{mol} / 1$, respectively. The neutralizing anti-human VEGF-A antibody was purchased from Abcam (3 $\mu \mathrm{g} / \mathrm{ml}$; cat. no. ab42609).

Lentivirus and stable cell lines. For S100A8 overexpression, full-length human S100A8 cDNA was amplified via polymerase chain reaction (PCR) and cloned into a lentivirus vector to establish an RBE cell line that stably expressed S100A8. Two clones were tested, and clone A was selected for subsequent experiments. For S100A8 knockdown, lentivirus encoding a specific shRNA against S100A8 was used to establish a stable HCCC-9810 cell line with S100A8 knockdown. Two clones were tested, and clone A was selected for subsequent experiments (target sequence: ACTCTATCATCGACGTCTACT CGAGTAGACGTCGATGATAGAGT). S100A8 overexpression (HBLV-h-S100A8-3-flag-GFP-PURO) and interference lentiviruses (HBLV-h-S100A8-shRNA1-GFP-PURO) were purchased from Shanghai Genechem Co., Ltd., HCCC-9810 and RBE cells were seeded onto 6-well plates, and lentiviral infection was carried out at 50-70\% confluency. For infection, the cells were provided with $1 \mathrm{ml}$ of fresh culture medium, and $30 \mu$ of lentivirus $\left(1 \times 10^{8}\right.$ transforming units $\left./ \mathrm{ml}\right)$ was added to each well. After 48-72 h, the infection rate was observed using a fluorescence microscope, and S100A8 expression levels were detected by western blotting.

Immunoblotting. Immunoblotting analyses were performed as described previously (27). Antibodies against S100A8 (cat. no. ab180735; Abcam), VEGF (cat. no. ab52917; Abcam), NF-kB p65 (cat. no. 8242; Cell Signaling Technology, Inc.) and phosphorylated (p-) NF-кB p65 Ser536 (cat. no. 3033; Cell Signaling Technology, Inc.) were used at 1:1,000 dilution. Membranes were washed with TBST for $30 \mathrm{~min}$ and incubated with an HRP-conjugated anti-rabbit secondary antibody (1:4,000; cat. no. ab6721; Abcam) for $2 \mathrm{~h}$ at room temperature.

Immunohistochemistry (IHC). The expression of S100A8 in paraffin-embedded clinical samples was investigated using IHC, according to a previously described protocol (28). Antibodies against S100A8 (1:200; cat. no. ab180735; Abcam) and VEGF (1:200; cat. no. ab52917; Abcam) were 
used. IHC staining of S100A8 and VEGF revealed both membrane and cytoplasmic localization. Hematoxylin and eosin (H\&E) staining of liver and spleen tumor tissue sections from mice was performed, as previously described (29). The immunostained tissue slides were scored according to stain intensity ( 0 , no staining; 1 , light staining; 2 , moderate staining; and 3, intense staining) multiplied by a distribution score $(1$, staining of $0-33 \%$; 2 , staining of 33-66\%; and $3,>66 \%$ staining). The final score was grouped as low expression [negative, (0) or low (1-2) scores], medium expression (moderate score, 3-4) or high expression (high score, 6-9) for further non-parametric tests. Each immunostained slide was scored by two pathologists in a double-blind manner using a light microscope.

Tumor cell migration assay. Tumor cell migration assays were performed using Transwell inserts (Corning, Inc.) with $8 \mu \mathrm{m}$ pores. Tumor cells $\left(2 \times 10^{5}\right)$ in $0.2 \mathrm{ml}$ of serum-free medium were seeded in the upper chamber of the insert, and $0.8 \mathrm{ml}$ of medium containing $10 \%$ FBS was added to the lower chamber. Cells were cultured for $12 \mathrm{~h}$ in a humid environment at $37^{\circ} \mathrm{C}$ with $5 \% \mathrm{CO}_{2}$. Cells remaining in the upper part of the transwell were removed with a cotton swab. Migrated cells were then stained with $0.5 \%$ crystal violet, and the number of cells per field was determined using a light microscope (Olympus Corporation; magnification, x200).

Tumor cell/HUVEC co-culture migration assay. HUVEC migration assays were performed using Transwell inserts (Corning, Inc.) with $8 \mu \mathrm{m}$ pores. HUVECs $\left(1 \times 10^{5}\right)$ in $0.2 \mathrm{ml}$ of serum-free medium were seeded in the upper chamber, and $0.8 \mathrm{ml}$ of tumor cell culture supernatant was added to the lower chamber. For the tumor cell supernatant, tumor cells $\left(5 \times 10^{5}\right)$ were cultured for $24 \mathrm{~h}$ in $1.0 \mathrm{ml}$ of medium containing $10 \% \mathrm{FBS}$ in a humid environment at $37^{\circ} \mathrm{C}$ and with $5 \% \mathrm{CO}_{2}$. HUVECs were allowed to migrate for $5 \mathrm{~h}$. Then, cells remaining in the upper part of the Transwell were removed with a cotton swab. Migrated cells on the lower part of the Transwell were stained with $0.5 \%$ crystal violet, and the number of cells per field was determined using a light microscope (Olympus Corporation; magnification, x200). In some experiments (Fig. S2), tumor cells $\left(2 \times 10^{5} / \mathrm{ml}\right)$ in $0.2 \mathrm{ml}$ of serum-free medium were added to the upper chamber and HUVECs were placed into the lower chamber, and migration of lentivirus-transduced tumor cells or control cells was observed.

HUVEC tube formation assay. For HUVEC tube formation assays, $0.3 \mathrm{ml}$ of Matrigel (BD Biosciences) was pipetted into a 24-well plate and then allowed to solidify for $1 \mathrm{~h}$ at $37^{\circ} \mathrm{C}$. HUVECs $\left(1 \times 10^{5}\right)$ in $0.2 \mathrm{ml}$ of conditioned medium were seeded into each well and incubated for $10 \mathrm{~h}$. The average number of HUVEC tubule structures per field was determined using a light microscope (Olympus Corporation; magnification, x100).

ELISA. VEGF levels in tumor cells and tissues were detected using a human VEGFELISA kit (cat.no.DY293B; R\&D Systems, Inc.), according to the manufacturer's instructions. In addition, the S100A8 levels in the CCA tissue samples were determined using an ELISA kit (cat. no. DY4570-05; R\&D Systems, Inc.), according to the manufacturer's instructions.
In vivo experiments. After anesthetizing with $1 \%$ sodium pentobarbital (60 mg/kg; Sigma-Aldrich; Merck KGaA) by intraperitoneal injection, a median abdominal incision of $1 \mathrm{~cm}$ was made under the xiphoid of nude mice. For experimental liver metastasis, RBE and HCCC-9810 cells were trypsinized and resuspended in PBS, and $5 \times 10^{5}$ cells or the indicated number of cells (in $0.1 \mathrm{ml}$ of PBS) were injected into the spleen of the mice. After 45 days, a 7.0 T small animal MRI (Bruker Biospec) was used to scan the mice and to observe metastasis. Mice were sacrificed at 45 days after injection (preliminary experiments were performed to determine the optimal time after injection to evaluate metastasis; data not shown), livers were isolated and fixed in $10 \%$ neutral-buffered formalin for $24 \mathrm{~h}$ at room temperature, and then dehydrated and embedded in paraffin. Metastatic foci on the surface of the livers were counted under a dissecting microscope, and the nodule size was measured.

Distant initial dissemination of tumor cells can be observed with the first few hours after the tumor cells enter the blood circulation, which is a key step to the metastatic cascade (30). For experimental initial liver colonization, $5 \times 10^{5} \mathrm{RBE}$ and HCCC-9810 cells were preloaded with Vybrant DiO Cell-labelling Solution (cat. no. V22886; Invitrogen; Thermo Fisher Scientific, Inc.) for $15 \mathrm{~min}$ at $37^{\circ} \mathrm{C}$ following the manufacturer's instructions. Cells were then injected into the spleen of the mice, as aforementioned. After $6 \mathrm{~h}$, livers were isolated, embedded in OCT compound (Tissue-Tek; Sakura Finetek USA, Inc.) and frozen in liquid nitrogen. Liver sections $(8 \mu \mathrm{m}$ thickness) were analyzed using an Olympus fluorescence microscope (VS120; Olympus Corporation), and the number of RBE and HCCC-9810 cells (green signal) was determined.

To assess tumor volumes, the longest (length) and shortest (width) diameters of the metastatic tumor foci in the liver were measured, and the volumes were calculated using the following formula: Length $\mathrm{x}$ width $^{2} \mathrm{x} 0.52$. The maximum volume of liver tumors was $91 \mathrm{~mm}^{3}$, and the maximum diameter was $7 \mathrm{~mm}$.

Statistical analysis. Data were analyzed with Prism 6.0 (GraphPad Software, Inc.) or SPSS 19.0 software (IBM Corp.). For categorical data, chi-square analysis or Fisher's exact test was used. Kaplan-Meier and Cox proportional hazards regression analysis were applied to assess overall survival. Experiments were repeated at least three times independently. Comparisons among multiple groups were made using ANOVA followed by least significant difference post hoc test. Normally distributed data are presented as the mean \pm standard error and were analyzed using Student's t-test. Non-normally distributed data were analyzed using Mann-Whitney U test. Spearman rank correlation coefficient was used to analyze the association between the protein expression levels of S100A8 and VEGF. $\mathrm{P}<0.05$ was considered to indicate a statistically significant difference.

\section{Results}

S100A8 is highly expressed in CCA, and its expression is closely associated with CCA severity. To investigate the role of S100A8 in CCA, pathological CCA tumor tissue and adjacent normal tissue specimens were collected from 41 patients with 
A

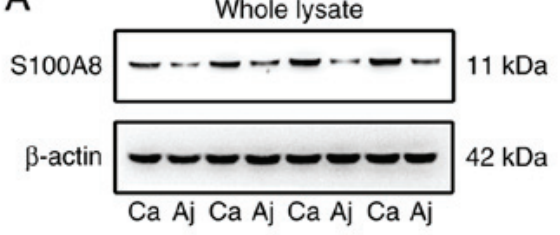

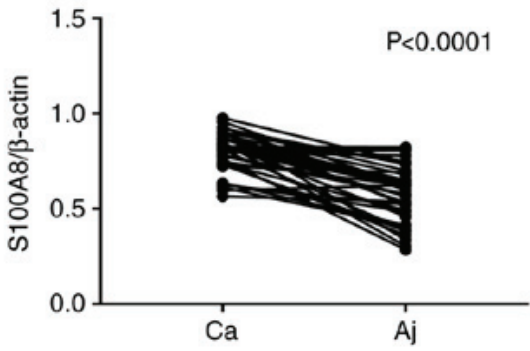

B

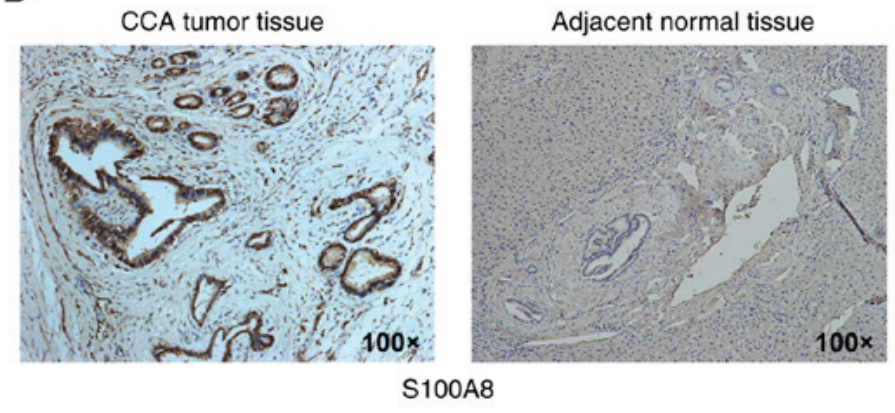

C

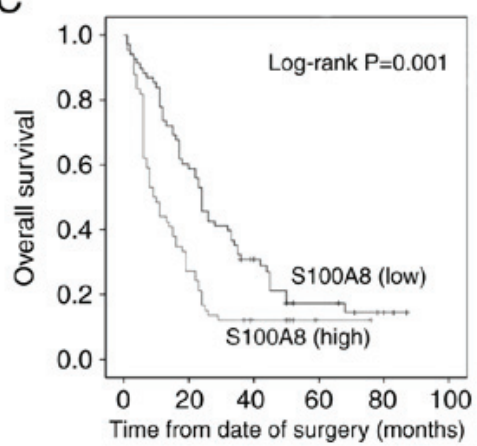

Figure 1. S100A8 is highly expressed in CCA, and its expression is associated with CCA severity. (A) Protein expression levels of S100A8 were detected by western blotting in 41 tumor tissues and adjacent normal tissues from patients with CCA. Representative blots from 4 paired samples are shown. (B) Representative immunohistochemical staining of S100A8 in CCA tumor (high expression) and adjacent normal tissues (low expression). (C) Kaplan-Meier plot for overall survival of 134 patients wih CCA with low or high S100A8 expression. Patients were divided in the two groups based the mean expression level. S100A8, S100 calcium-binding protein A8; CCA, cholangiocarcinoma; Ca, carcinoma; Aj, adjacent normal.

CCA.S100A8 expression was found to be higher in CCA tissues compared with adjacent normal tissues, as detected by western blot analysis (Fig. 1A). In addition, increased S100A8 expression was observed in CCA primary tumor tissues compared with the adjacent normal tissues by immunohistochemical staining (Fig. 1B and Fig. S1A). To further evaluate the association between S100A8 protein expression and CCA malignancy, the S100A8 protein levels were detected in 134 pathological specimens from patients with CCA via ELISA. S100A8 expression levels were significantly associated with tumor differentiation status and lymph node metastasis, but not with age or sex (Table I). In accordance with this finding, S100A8 expression levels were also significantly associated with poor prognosis in patients with CCA following surgical resection, as evaluated by multivariate Cox proportional hazards regression analysis (Table II). In addition, Kaplan-Meier survival analysis revealed that high S100A8 expression was correlated with a significant reduction in overall survival of patients with CCA (Fig. 1C). Because S100A8 is known to be highly expressed by neutrophils, the relationship between S100A8 expression and neutrophil numbers was investigated in the 134 patients with CCA in the present study, but no significant correlation of S100A8 expression with the number of neutrophils in the peripheral blood was observed (Fig. S1B). The present results indicated that S100A8 expression was significantly associated with the severity of CCA.

S100A8 facilitates CCA cell invasion and migration in vitro. Next, the present study hypothesized that S100A8 may be involved in promoting CCA metastasis. To investigate this, the RBE CCA cell line, which has low intrinsic S100A8 protein expression, was transduced with lentivirus to overexpress
S100A8. The transduction efficiency was confirmed by immunoblotting; the results revealed that S100A8 protein expression was significantly upregulated in the RBE-overexpressing cells compared with the negative control cells (Fig. 2A; clone A was selected for further experiments). In vitro Transwell assays revealed that S100A8-overexpressing RBE cells displayed a significant increase in migration ability compared with control cells (Fig. 2C). Transwell invasion assays (with Matrigel-coated inserts) gave similar results for cell invasion (data not shown).

To determine whether silencing of S100A8 expression could attenuate the migration of CCA cells, another CCA cell line, HCCC-9810, which has high intrinsic S100A8 expression, was used. Knockdown of S100A8 in HCCC-9810 cells was established via a shRNA-encoding lentivirus, and successful transduction was confirmed by western blotting (Fig. 2B; clone A was selected for further experiments). In vitro Transwell assays revealed that S100A8-silenced HCCC-9810 cells had significantly reduced migration ability compared with control cells (Fig. 2D). These results indicated that S100A8 may participate in promoting CCA migration.

S100A8 enhances the tumor-induced migration of vascular endothelial cells in vitro. Because angiogenesis is a key process contributing in malignant tumor growth, invasion and metastasis, the role of S100A8 in promoting angiogenesis was investigated next. The ability of RBE cells overexpressing S100A8 to promote migration of HUVECs was analyzed using a Transwell assay. Conditioned media from S100A8-overexpressing and control RBE cells was placed into the lower chamber of the Transwell system, and HUVECs were placed into the upper chamber. The number of migratory HUVECs was found to be significantly increased towards the 
Table I. Association between S100A8 expression levels and clinicopathological features in 134 patients with cholangiocarcinoma.

\begin{tabular}{lccc}
\hline & \multicolumn{2}{c}{ S100A8 expression } & \\
\cline { 2 - 3 } $\begin{array}{l}\text { Clinicopathological } \\
\text { feature }\end{array}$ & Low $68(\%)$ & High $66(\%)$ & P-value \\
\hline Sex & $43(63)$ & $46(70)$ & 0.468 \\
Male & $25(37)$ & $20(30)$ & \\
Female & & & 0.729 \\
Age (years) & $30(44)$ & $32(48)$ & \\
$<55$ & $38(56)$ & $34(52)$ & \\
$\geq 55$ & & & 0.037 \\
Differentiation & $19(28)$ & $24(36)$ & \\
Poor & $43(63)$ & $42(64)$ & \\
Moderate & $6(9)$ & $0(0)$ & \\
High & & & 0.01 \\
Lymph node metastasis & $30(44)$ & $44(67)$ & \\
Yes & $38(56)$ & $22(33)$ & \\
No & &
\end{tabular}

S100A8, S100 calcium-binding protein A8.

Table II. Multivariate Cox proportional hazards regression analysis for S100A8 expression levels and overall survival in patients with cholangiocarcinoma.

\begin{tabular}{lcc}
\hline Factor & Hazard ratio (95\% CI) & P-value \\
\hline $\begin{array}{l}\text { Expression of S100A8 } \\
\text { (low vs. high) }\end{array}$ & $1.654(1.130-2.421)$ & 0.01 \\
Sex & $0.850(0.568-1.272)$ & 0.429 \\
Age & $1.404(0.960-2.055)$ & 0.08 \\
Differentiation & $0.610(0.420-0.884)$ & 0.009 \\
Lymph node metastasis & $0.312(0.206-0.473)$ & $<0.001$ \\
\hline
\end{tabular}

S100A8, S100 calcium-binding protein A8; CI, confidence interval.

conditioned media of the S100A8-overexpressing RBE cells compared with the control group (Fig. 3A). However, no migration of lentivirus-transduced RBE tumor cells or control cells was observed when HUVECs were placed into the lower chamber and lentivirus-transduced RBE cells and control cells were placed into the upper chamber (Fig. S2). In addition, these observations were further confirmed using the second CCA cell line, HCCC-9810; S100A8 knockdown reduced the ability of HCCC-9810 to induce HUVEC migration (Fig. 3B). These findings indicated that S100A8 had a pro-angiogenesis function in CCA.

S100A8 promotes CCA dissemination and metastasis in vivo. To investigate whether S100A8 increases CCA metastasis in vivo, a liver experimental metastasis model was established in mice. Control RBE and S100A8-overexpressing RBE cells were injected into the spleens of wild-type mice, and then, liver metastasis was monitored. Both S100A8-overexpressing RBE cells and control RBE cells formed metastatic foci in the liver, but S100A8-overexpressing RBE cells resulted in significantly increased numbers of metastatic foci (Fig. 4A, C and D). By contrast, S100A8 knockdown reduced the metastatic ability of HCCC-9810 CCA cells in vivo (Fig. 4B). To investigate whether S100A8 protein overexpression or knockdown affects metastatic growth, the volume of the liver metastatic foci was measured, and no significant difference was found between the S100A8-overexpressing, the S100A8-silenced and the control CCA cells (data not shown).

Tumor metastasis is primarily dependent on hematogenous dissemination in the blood circulation (30). To further investigate whether S100A8-overexpressing RBE cells increase metastatic dissemination in the liver, equal quantities of fluorescently-labelled RBE and S100A8-overexpressing RBE cells were injected into the spleen of mice. Compared with control cells, S100A8-overexpressing RBE cells resulted in a significantly increased liver metastatic tumor burden (Fig. 4E). In addition, fluorescence microscopy analysis revealed that the tumor cells were primarily distributed around the vasculature (Fig. 4E), indicating that these tumor cells may have entered surrounding tissues through the blood vessels to form metastases. These data suggested that S100A8 may enhance the dissemination and metastasis ability of CCA cells in vivo.

S100A8 upregulates VEGF expression in CCA cells. Given that VEGF is a key factor in tumor invasion and metastasis $(7,22)$, the present study next evaluated the VEGF expression levels in the patient tissues. The results demonstrated that VEGF was more highly expressed in CCA tissues compared with adjacent normal tissues from patients with CCA (Fig. 5A and B, and Fig. S3). These results were similar to the S100A8 expression results. Consistently, VEGF expression was also significantly associated with tumor differentiation status, lymph node metastasis and poor prognosis in patients with CCA following surgical resection (Tables III and IV). In addition, Kaplan-Meier survival analysis revealed that high VEGF expression was associated with a significant decrease in the overall survival of patients with CCA (Fig. 5C).

Treatment of HUVECs with supernatants from S100A8-overexpressing RBE cells distinctly promoted the formation of vascular tube-like structures (Fig. 5D). In addition, a previous study has reported that $\mathrm{S100A} 8$ can promote the secretion of vasoactive factors, including VEGF (7). These findings suggested that VEGF may be responsible for the role of S100A8 in facilitating CCA dissemination and metastasis. Notably, overexpression or knockdown of S100A8 significantly increased or reduced the secretion of VEGF from CCA cells, respectively (Fig. 5E and F). In addition, S100A8 expression levels were significantly correlated with VEGF expression levels in the tissues of the 134 patients with CCA (Fig. 5G). Multivariate Cox proportional hazards regression analyses revealed that combined high S100A8 and high VEGF expression levels were significantly associated with poor prognosis in patients with CCA following surgical resection (Table V). Finally, inhibition of VEGF via a neutralizing antibody abrogated the S100A8-enhanced migration of RBE cells 


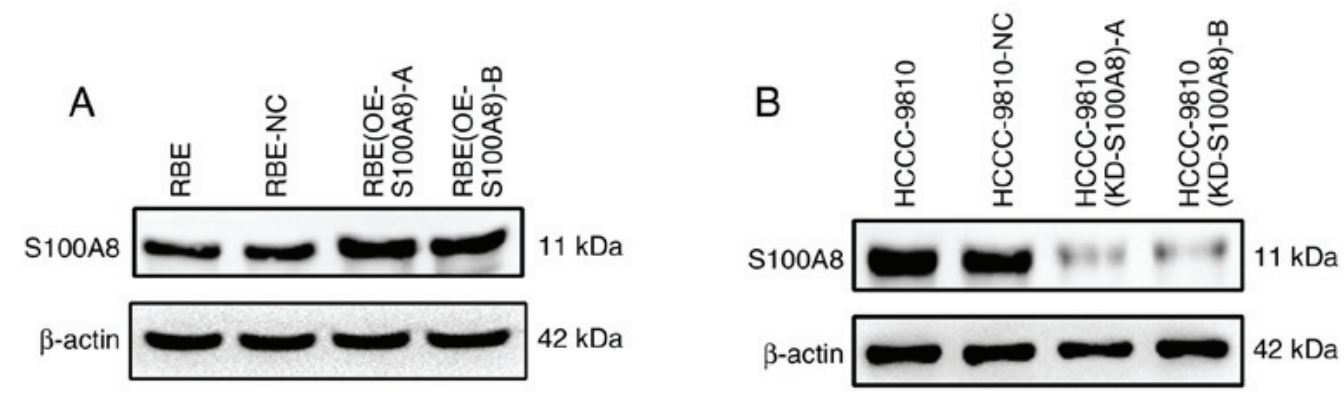

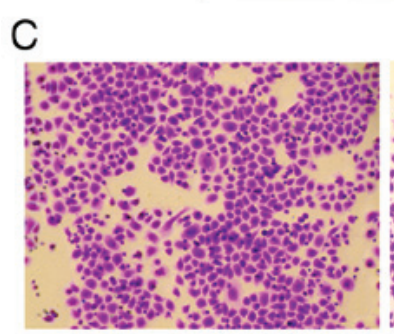

RBE

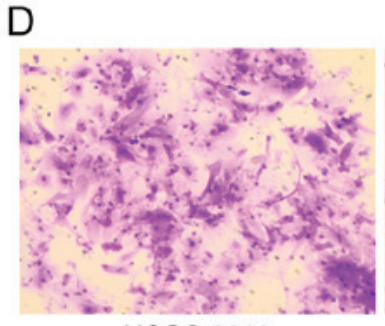

HCCC-9810

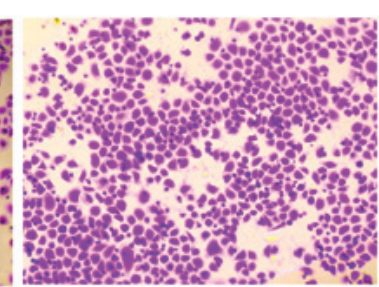

RBE-NC

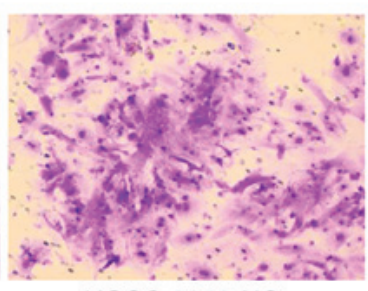

HCCC-9810-NC

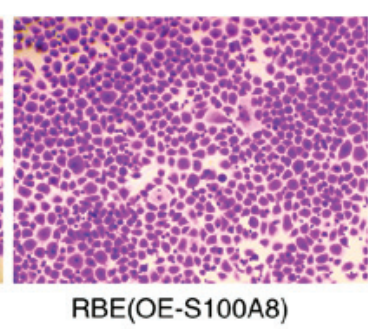

RBE(OE-S100A8)

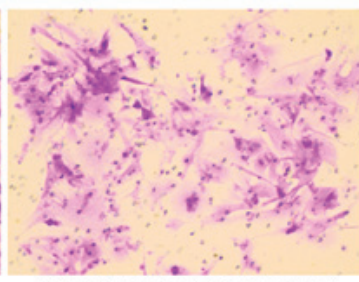

HCCC-9810(KD-S100A8)
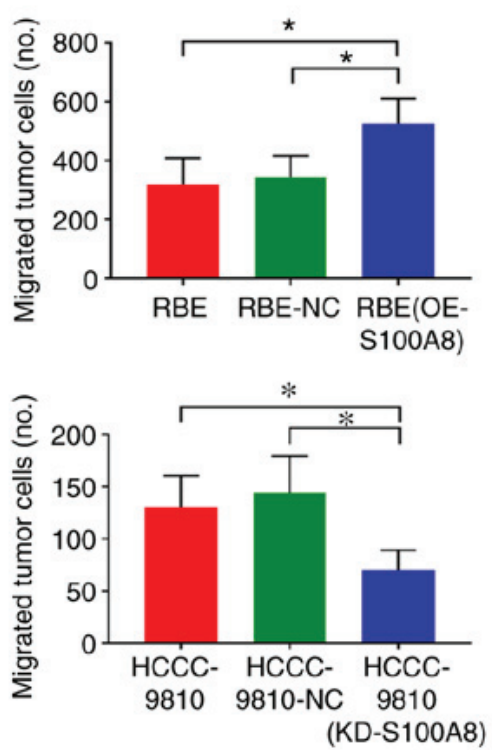

Figure 2. S100A8 facilitates CCA cell migration in vitro. (A) Overexpression of S100A8 in the RBE CCA cell line following lentivirus transduction was confirmed by western blotting. Two separate overexpressing clones, (OE-S100A8)-A and (OE-S100A8)-B, were tested. (B) Knockdown of S100A8 in the HCCC-9810 CCA cell line following lentivirus transduction was confirmed by western blotting. Two separate knockdown clones, (KD-S100A8)-A and (KD-S100A8)-B, were tested. (C) Transwell migration assays of control parental, lentiviral control-transduced, and S100A8-overexpressing RBE cells or (D) S100A8-knockdown HCCC-9810 cells. "P<0.05 with comparisons indicated by brackets. S100A8, S100 calcium-binding protein A8; CCA, cholangiocarcinoma; OE, overexpression; KD, knockdown; NC, negative control.

A

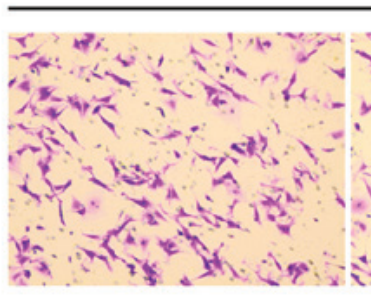

RBE

B
HUVEC

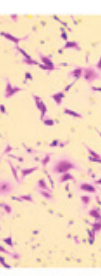

RBE-NC

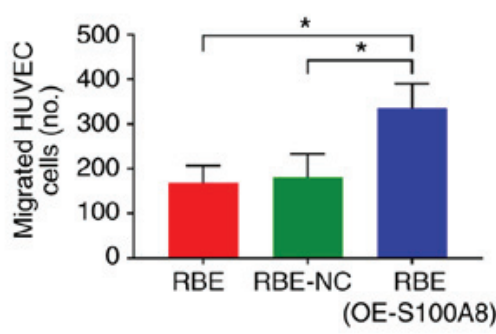

RBE(OE-S100A8)

HUVEC
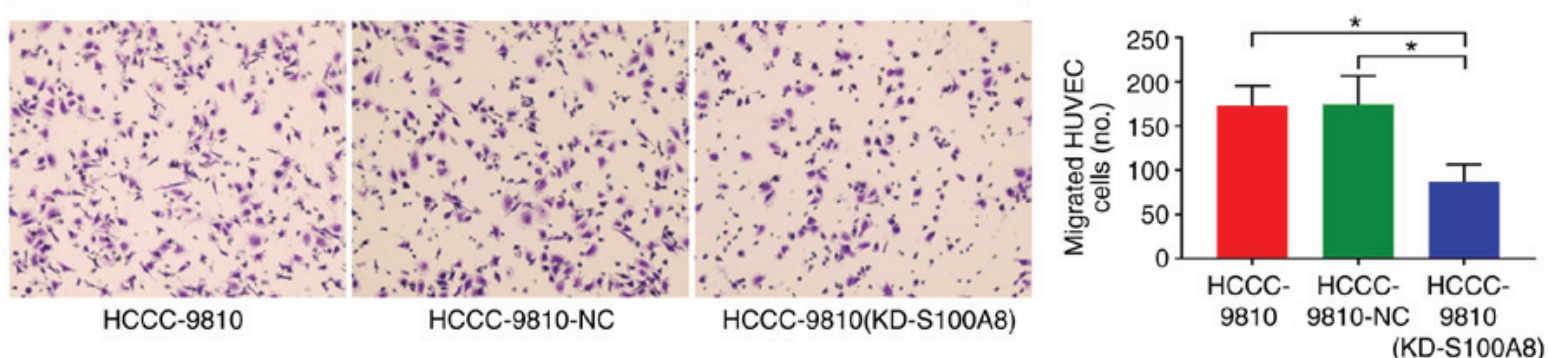

Figure 3. S100A8 enhances tumor-induced migration of vascular endothelial cells in vitro. HUVEC migration was assessed by Transwell migration assays in response to (A) RBE and (B) HCCC-9810 cholangiocarcinoma cell lines after overexpression or knockdown of S100A8, respectively. * $<0.05$ with comparisons indicated by brackets. S100A8, S100 calcium-binding protein A8; HUVEC, human umbilical vein endothelial cell; OE, overexpression; KD, knockdown; $\mathrm{NC}$, negative control. 
A

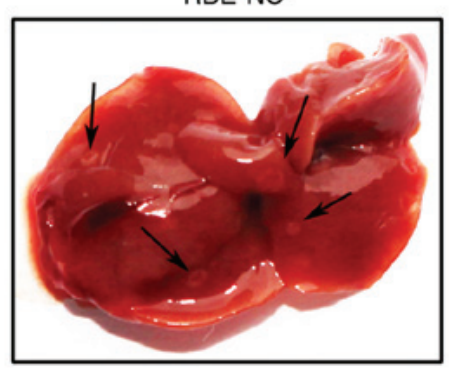

B

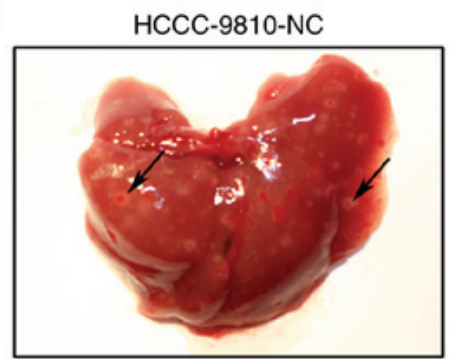

C
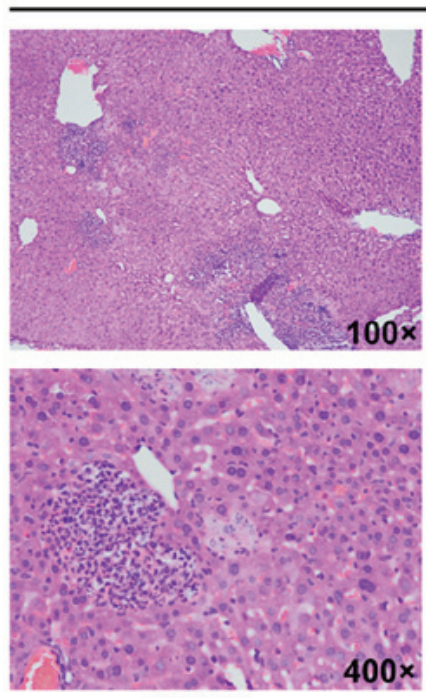

RBE-NC
RBE(OE-S100A8)

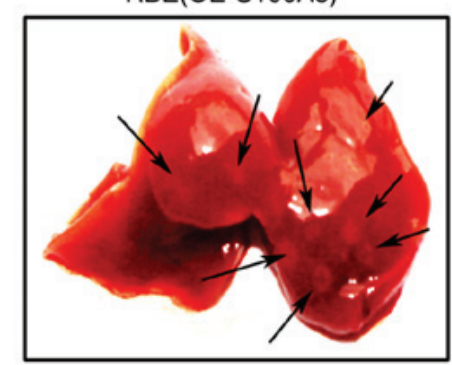

HCCC-9810(KD-S100A8)

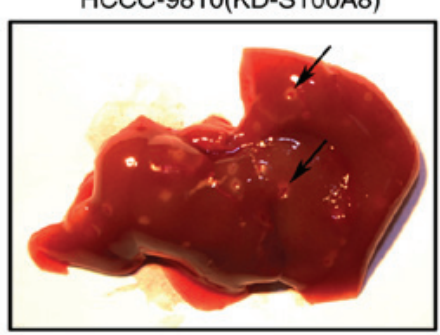

D
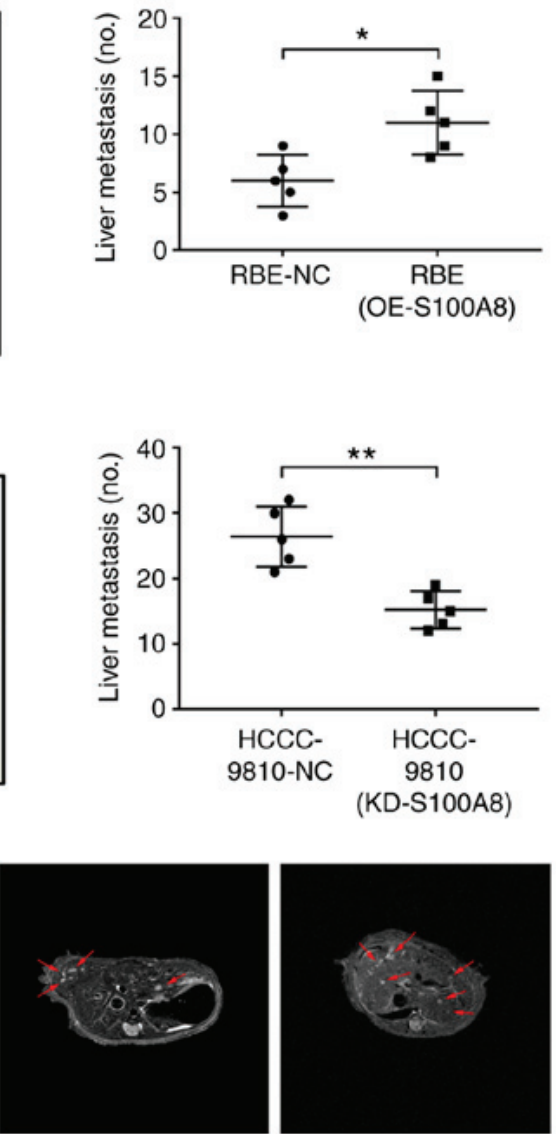

RBE-NC

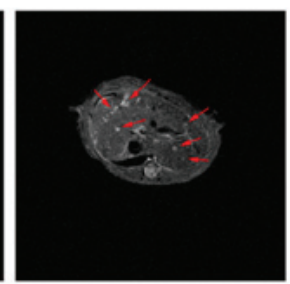

RBE(OE-S100A8)

E

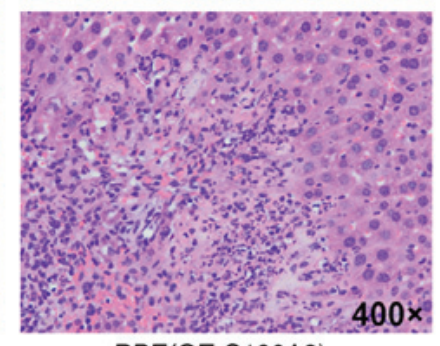

RBE(OE-S100A8)

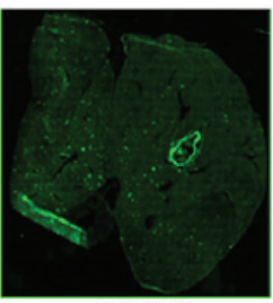

RBE-NC

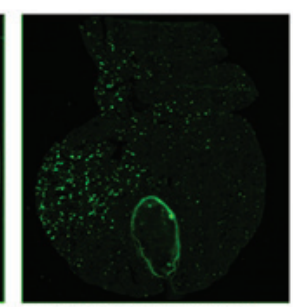

RBE(OE-S100A8)

Figure 4. S100A8 promotes CCA dissemination and metastasis in vivo. (A) Representative photographs of liver metastasis foci in mice 45 days after splenic injection of RBE cells with or without S100A8 overexpression ( $\mathrm{n}=5$ per group). Quantification of the numbers of liver metastatic foci is shown in the right. (B) Representative photographs of liver metastasis foci in mice 45 days after splenic injection of HCCC-9810 cells with or without S100A8 knockdown ( $=5$ per group). Quantification of the number of liver metastatic foci is shown on the right. (C) Representative images of metastatic foci (magnification, $\mathrm{x} 100$ and $\mathrm{x} 400$ ) in hematoxylin and eosin-stained liver tissue sections from mice injected with control or S100A8-overexpressing RBE cells. (D) Magnetic resonance imaging of liver metastasis foci in mice 45 days after splenic injection of RBE cells with or without S100A8 overexpression. (E) The distribution of disseminated tumor cells in murine livers was examined by fluorescence microscopy $5 \mathrm{~h}$ after splenic injection of RBE cells with or without $\mathrm{S} 100 \mathrm{~A} 8$ overexpression. * $\mathrm{P}<0.0$ and ${ }^{* *} \mathrm{P}<0.01$. S100A8, S100 calcium-binding protein A8; CCA, cholangiocarcinoma; OE, overexpression; KD, knockdown; NC, negative control.

(Fig. 5H). Therefore, these results suggested that S100A8 may play a crucial role in CCA progression through upregulation of VEGF.

S100A8 increases VEGF expression by activating the $T L R 4 / N F-\kappa B$ pathway. Finally, the present study sought to determine the underlying mechanism by which S100A8 upregulates VEGF expression. TLR4 has been reported to be a receptor of $\mathrm{S} 100 \mathrm{~A} 8$, and $\mathrm{NF}-\kappa \mathrm{B}$, which is downstream of TLR4, is responsible for VEGF production $(31,32)$. Therefore, it was speculated that S100A8 might promote
VEGF expression through the TLR4/NF- $\kappa$ B pathway. As anticipated, overexpression of S100A8 in RBE cells activated the NF- $\kappa \mathrm{B}$ pathway (Fig. 6A). Notably, TLR4 and $\mathrm{NF}-\kappa \mathrm{B}$ inhibition completely abrogated the S100A8 overexpression-induced upregulation of VEGF expression in RBE cells (Fig. 6E), and significantly inhibited RBE cell migration (Fig. 6C). In addition, results from these assays in HCCC-9810 cells revealed that the NF- $\kappa \mathrm{B}$ pathway was crucial to the migration of the CCA cells and the secretion of VEGF (Fig. 6B, D and F). Taken together, the present findings demonstrated that the TLR4/NF- $\kappa$ B pathway mediated 
A

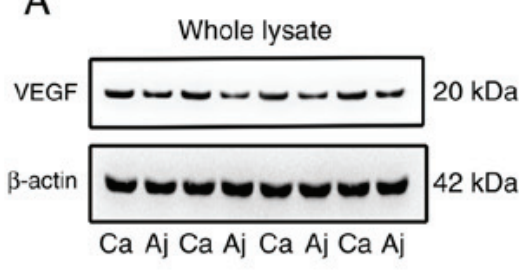

B

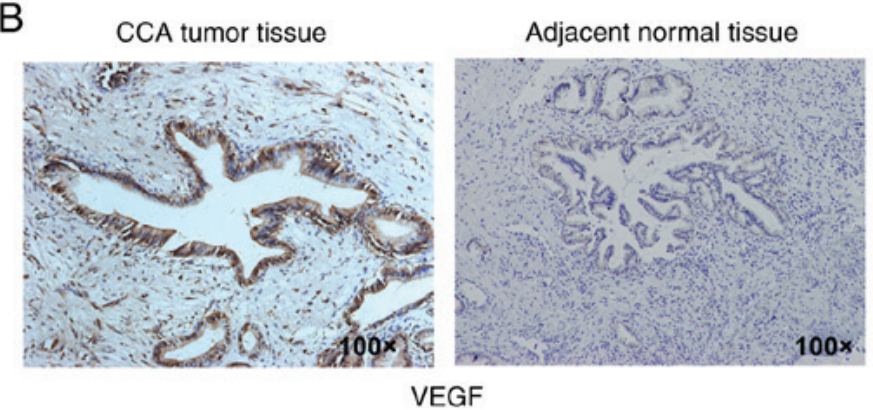

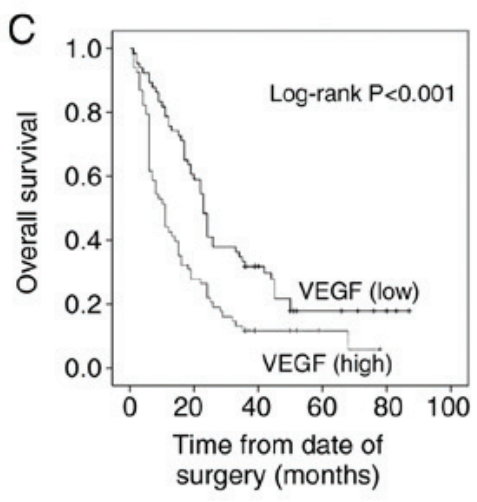

E

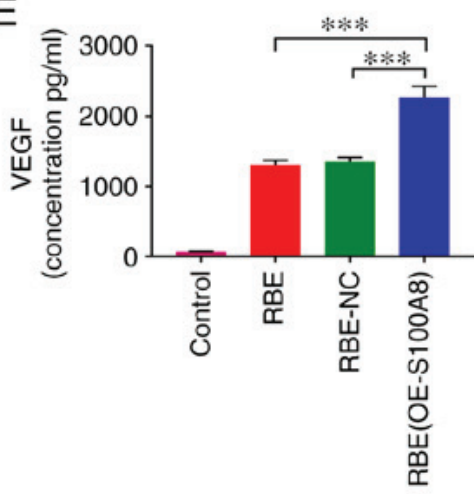

HUVECs

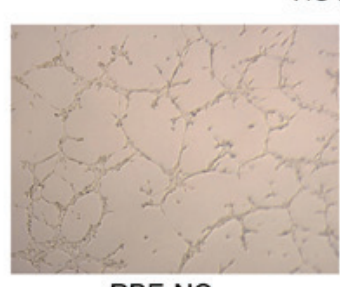

RBE-NC

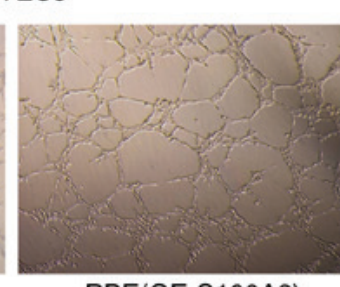

RBE(OE-S100A8)

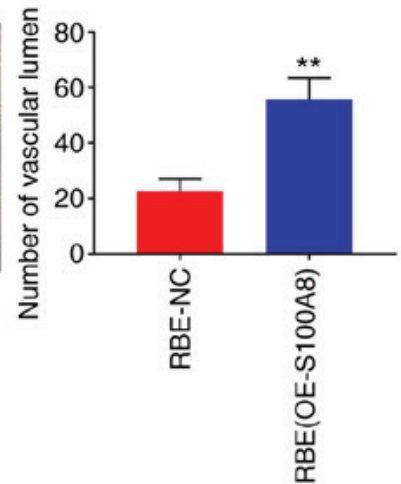

$\mathrm{F}$

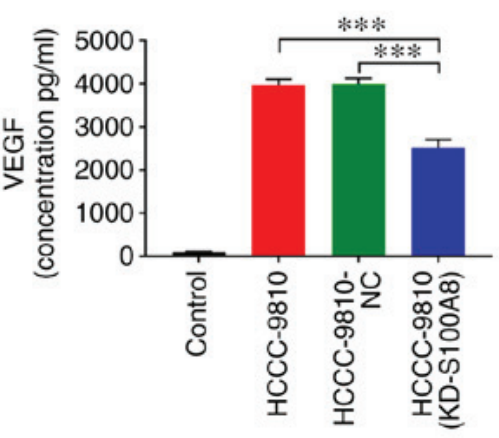

G

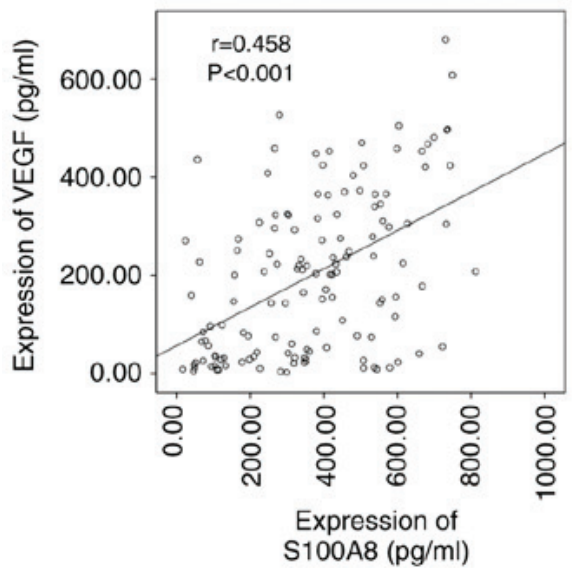

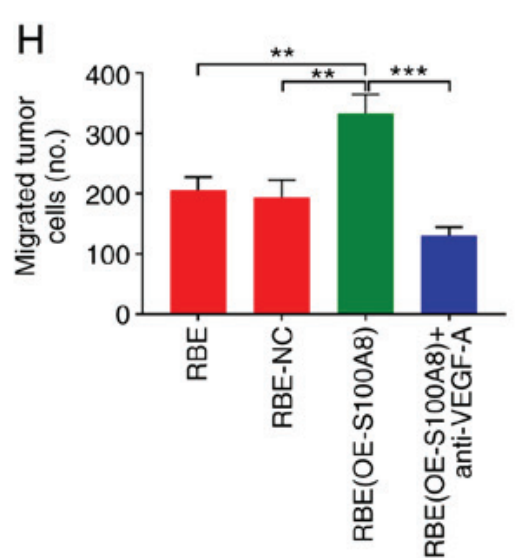
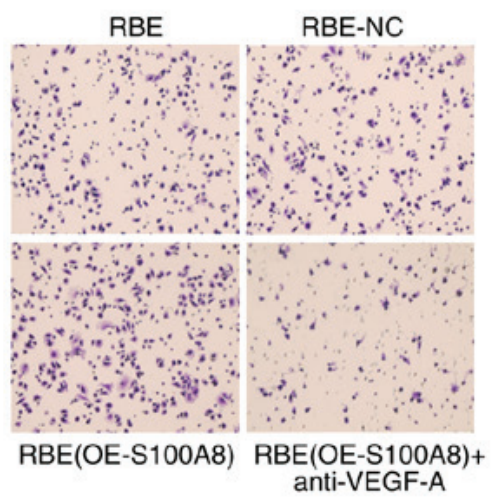

Figure 5. S100A8 upregulates VEGF expression in CCA cells. (A) VEGF protein expression levels were determined by western blotting in 41 tumor tissues and adjacent normal tissues from patients with CCA. Representative blots from 4 paired samples are shown. (B) Representative images from immunohistochemical staining of VEGF in CCA tumor (high expression) and adjacent normal tissues (low expression). (C) Kaplan-Meier plot for overall survival of 134 CCA patients with low or high VEGF expression (based the mean expression level). (D) Representative images and quantification of vascular tube-like formation in HUVECs treated with supernatants from RBE cells with or without S100A8 overexpression (n=3). (E) RBE cells with or without S100A8 overexpression were cultured in $1.0 \mathrm{ml}$ of medium containing $10 \% \mathrm{FBS}$ for $24 \mathrm{~h}$. The total VEGF levels were then determined by ELISA. (F) HCCC-9810 cells with or without S100A8 knockdown were cultured in $1.0 \mathrm{ml}$ of medium containing 10\% FBS for $24 \mathrm{~h}$. The total VEGF levels were then determined by ELISA. (G) Correlation between S100A8 and VEGF protein levels in 134 patients with CCA, as determined by ELISA. (H) Migration of RBE cells (with or without S100A8 overexpression) following treatment with a neutralizing VEGF antibody. ${ }^{* *} \mathrm{P}<0.01$ and ${ }^{* * * *} \mathrm{P}<0.001$, with comparisons indicated by brackets. S100A8, S100 calcium-binding protein A8; VEGF, vascular endothelial growth factor; CCA, cholangiocarcinoma; HUVEC, human umbilical vein endothelial cell; $\mathrm{Ca}$, carcinoma; $\mathrm{Aj}$, adjacent normal; $\mathrm{OE}$, overexpression; $\mathrm{KD}$, knockdown; NC, negative control. 

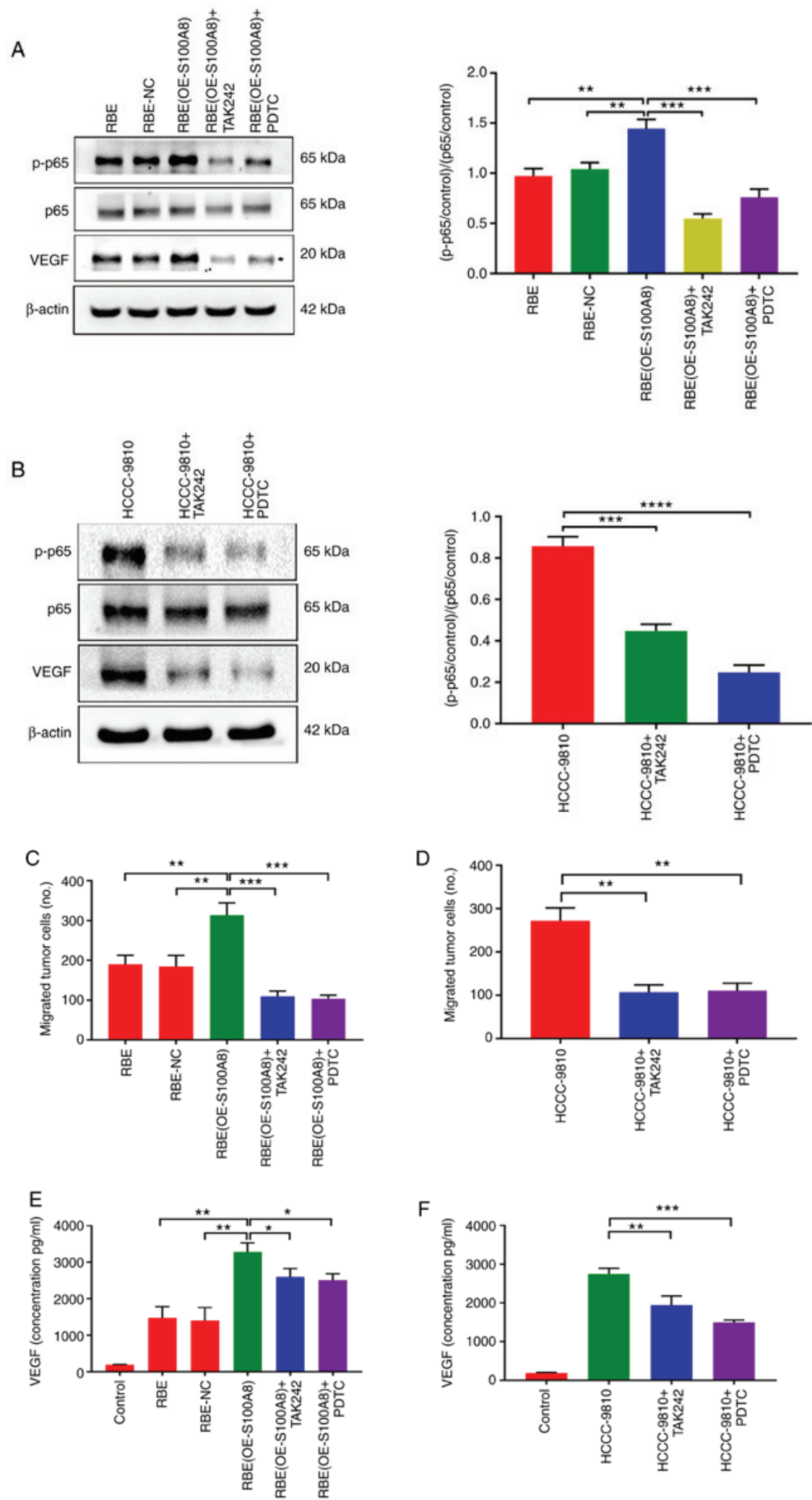

Figure 6. S100A8 increases VEGF expression by activating the TLR4/NF-kB pathway. (A) p-p65, total p65 and VEGF protein expression levels were determined by western blotting in RBE parental, NC and S100A8-overexpressing cells, with or without treatment with the TAK242 and PDTC inhibitors. (B) p-p65, total p65 and VEGF protein expression levels were determined by western blotting in HCCC-9810 cells with or without treatment with the TAK242 and PDTC inhibitors. (C) RBE parental, NC and S100A8-overexpressing cells, with or without treatment with the TAK242 and PDTC inhibitors, were allowed to migrate in Transwell chambers for $12 \mathrm{~h}$, then the numbers of migrated cells were determined by microcopy (magnification, x200). (D) HCCC-9810 cells with or without treatment with the TAK242 and PDTC inhibitors were allowed to migrate in Transwell chambers for $12 \mathrm{~h}$, then the numbers of migrated cells were determined by microcopy (magnification, x200). (E) RBE parental, NC and S100A8-overexpressing cells, with or without treatment with the TAK242 and PDTC inhibitors, were seeded separately into 24 -well dishes in $1 \mathrm{ml}$ of medium containing $10 \%$ FBS and cultured for $24 \mathrm{~h}$. The total VEGF levels were then determined by ELISA. (F) HCCC-9810 cells with or without treatment with the TAK242 and PDTC inhibitors were seeded separately into 24 -well dishes in $1 \mathrm{ml}$ of medium containing 10\% FBS and cultured for $24 \mathrm{~h}$. The total VEGF levels were then determined by ELISA. "P $<0.05,{ }^{* *} \mathrm{P}<0.01$ and ${ }^{* * *} \mathrm{P}<0.001$, with comparisons indicated by brackets. S100A8, S100 calcium-binding protein A8; VEGF, vascular endothelial growth factor; TLR, Toll-like receptor; p-, phosphorylated; NC, negative control; OE, overexpression; KD, knockdown. 
Table III. Association between VEGF expression levels and clinicopathological features in 134 patients with cholangiocarcinoma.

\begin{tabular}{lccc}
\hline & \multicolumn{2}{c}{ VEGF expression } & \\
\cline { 2 - 3 } $\begin{array}{l}\text { Clinicopathological } \\
\text { feature }\end{array}$ & Low 68 (\%) & High $66(\%)$ & P-value \\
\hline Sex & $41(62)$ & $48(71)$ & 0.361 \\
Male & $25(38)$ & $20(29)$ & \\
Female & & & 0.392 \\
Age (years) & $28(42)$ & $34(50)$ & \\
$<55$ & $38(58)$ & $34(50)$ & \\
$\geq 55$ & & & 0.008 \\
Differentiation & $16(24)$ & $27(40)$ & \\
Poor & $44(67)$ & $41(60)$ & \\
Moderate & $6(9)$ & $0(0)$ & \\
High & & & \\
Lymph node metastasis & $29(44)$ & $45(66)$ & \\
Yes & $37(56)$ & $23(34)$ & \\
No & &
\end{tabular}

VEGF, vascular endothelial growth factor.

Table IV. Multivariate Cox proportional hazards regression analysis for VEGF expression levels and overall survival in patients with cholangiocarcinoma.

\begin{tabular}{lcr}
\hline Factor & Hazard ratio (95\% CI) & P-value \\
\hline $\begin{array}{l}\text { Expression of VEGF } \\
\text { (low vs. high) }\end{array}$ & $1.781(1.213-2.614)$ & 0.003 \\
Sex & $0.842(0.563-1.259)$ & 0.401 \\
Age & $1.498(1.020-2.201)$ & 0.039 \\
Differentiation & $0.619(0.424-0.903)$ & 0.013 \\
Lymph node metastasis & $0.307(0.202-0.466)$ & $<0.001$ \\
\hline
\end{tabular}

VEGF, vascular endothelial growth factor; CI, confidence interval.

the role of S100A8 in promoting VEGF expression in CCA cells.

\section{Discussion}

Patients with CCA have a poor prognosis and high mortality due to the increased invasiveness and early metastasis of CCA (33-35). Although many studies have focused on CCA, the molecular mechanisms underlying CCA invasion and metastasis have not been fully elucidated. The present study demonstrated for the first time that S100A8 promoted CCA migration and metastasis via the TLR4/NF- $\kappa \mathrm{B} / \mathrm{VEGF}$ signaling axis.

Previous studies have shown that S100A8 protein is localized in the cytoplasm of multiple cell types and that it has multiple biological functions, including regulating cell cycle progression, affecting cell differentiation and inducing cell
Table V. Multivariate Cox proportional hazards regression analysis for combined S100A8/VEGF expression levels and overall survival in patients with cholangiocarcinoma.

\begin{tabular}{lcr}
\hline Factor & Hazard ratio (95\% CI) & P-value \\
\hline Expression of high & $1.819(1.210-2.734)$ & 0.004 \\
S100A8/high VEGF & & \\
Sex & $0.896(0.599-1.340)$ & 0.593 \\
Age & $1.380(0.944-2.018)$ & 0.096 \\
Differentiation & $0.652(0.447-0.950)$ & 0.026 \\
Lymph node metastasis & $0.316(0.208-0.480)$ & $<0.001$ \\
\hline
\end{tabular}

S100A8, S100 calcium-binding protein A8; VEGF, vascular endothelial growth factor; CI, confidence interval.

apoptosis (36-38). S100A8 can also function as a cytokine that is primarily secreted by neutrophils to activate monocytes and macrophages $(39,40)$. Notably, other studies have observed increased expression of S100A8 protein in multiple tumor types $(37,41)$, however, the expression and role of S100A8 protein in malignant bile duct tumors have not been previously elucidated. The present study reported that S100A8 was more highly expressed in CCA tissues compared with adjacent normal tissues, suggesting that S100A8 may have a unique role in CCA. Additionally, S100A8 expression was significantly associated with CCA severity and poor clinical prognosis. Furthermore, in vitro and in vivo experiments revealed that S100A8 had a crucial role in CCA tumor migration and metastasis.

New blood vessels in tumor tissues are required for tumor growth and metastasis (42-44), and VEGF is well-established as a factor required to promote angiogenesis, which markedly enhances tumor invasion and metastasis (23). In the present study, through analysis of pathological specimens, it was demonstrated that VEGF expression levels were increased in CCA tumor tissues compared with adjacent normal tissues, and that they were significantly associated with the poor prognosis of CCA, which was similar to the S100A8 findings. Furthermore, in vitro overexpression or knockdown of S1000A8 in CCA cells resulted in increased or decreased, respectively, expression of VEGF. According to a previous study, the migration of endothelial cells induced by tumor cells greatly increases the microvessel density in tumors, thus serving a pivotal role in tumor invasion and metastasis $(7,45)$. In line with this notion, the present study confirmed that S100A8-overexpressing CCA cells increased the migration of endothelial cells, therefore potentially leading to an enhancement in tumor dissemination and metastasis ability. However, other studies have reported that a low S100A8 concentration promotes endothelial cell migration and expansion and enhances vascular permeability and a high S100A8 concentrations leads to necrosis of endothelial cells (46-48). Thus, the biological functions of S100A8 may be different depending on the cell or tumor type.

Multiple studies have reported that the NF- $\mathrm{NB}$ pathway has an important role in the progression multiple types of cancer, by promoting cell proliferation and inhibiting cell 
apoptosis $(49,50)$. In addition, the $\mathrm{NF}-\kappa \mathrm{B}$ pathway is responsible for generation of many of the cytokines associated with tumor angiogenesis, such as VEGF $(51,52)$. The current study provided experimental evidence that S100A8 promoted CCA cell migration, at least in part, through the TLR4/NF- $\mathrm{KB} / \mathrm{VEGF}$ signaling pathway. However, the possibility that there could be other mechanisms that also mediate the role of S100A8 in CCA migration and metastasis cannot be excluded, and further research will be required to fully elucidate this.

In conclusion, the present study highlighted the importance of S100A8 in upregulation of VEGF expression through activation of the TLR4/NF- $\kappa \mathrm{B}$ pathway, thereby providing a favorable microenvironment for tumor invasion and metastasis. Therefore, S100A8 may serve as a potential target for tumor metastasis. Additionally, the present findings suggested that S100A8 may be a candidate prognostic marker for CCA.

\section{Acknowledgements}

We thank the Institute of Hepatobiliary Surgery of Southwest Hospital for providing human cholangiocarcinoma tissue. We also thank the Statistical Teaching and Research Department of the Third Military Medical University for technical assistance.

\section{Funding}

This work was supported by grants from the National Natural Science Fund of China (nos. 81725019, 81502755 and 81500087) and the Scientific Research Project of The Chinese People's Liberation Army (grant no. AWS16J014).

\section{Availability of data and materials}

The datasets used and analyzed in the current study are available from the corresponding author upon reasonable request.

\section{Authors' contributions}

JW and YH designed and supervised all experiments. MC and $\mathrm{PZ}$ prepared the materials and contributed to data acquisition. YH, YX, CD, JL, YZ, JB and JZ assisted with the animal and molecular biology experiments. JC and PJ analyzed the data. SP and MH drafted the manuscript. All authors read and approved the final manuscript.

\section{Ethics approval and consent to participate}

Experiments were approved by the Ethics Committee of the Southwest Hospital of the Third Military Medical University of China. Written, informed consent was obtained from all participants.

\section{Patient consent for publication}

Not applicable.

\section{Competing interests}

The authors declare that they have no competing interests.

\section{References}

1. Razumilava $\mathrm{N}$ and Gores GJ: Cholangiocarcinoma. Lancet 383: 2168-2179, 2014.

2. Tyson GL and El-Serag HB: Risk factors for cholangiocarcinoma. Hepatology 54: 173-184, 2011.

3. Khan SA, Davidson BR, Goldin RD, Heaton N, Karani J, Pereira SP, Rosenberg WM, Tait P, Taylor-Robinson SD, Thillainayagam AV, et al: Guidelines for the diagnosis and treatment of cholangiocarcinoma: An update. Gut 61: 1657-1669, 2012.

4. Lim SY, Yuzhalin AE, Gordon-Weeks AN and Muschel RJ: Tumor-infiltrating monocytes/macrophages promote tumor invasion and migration by upregulating S100A8 and S100A9 expression in cancer cells. Oncogene 35: 5735-5745, 2016.

5. Yu LX, Yan L, Yang W, Wu FQ, Ling Y, Chen SZ, Tang L, Tan YX, Cao D, Wu MC, et al: Platelets promote tumour metastasis via interaction between TLR4 and tumour cell-released high-mobility group box1 protein. Nat Commun 5: 5256, 2014.

6. Gupta GP and Massagué J: Cancer metastasis: Building a framework. Cell 127: 679-695, 2006.

7. Brantley-Sieders DM, Fang WB, Hwang Y, Hicks D and Chen J: Ephrin-A1 facilitates mammary tumor metastasis through an angiogenesis-dependent mechanism mediated by EphA receptor and vascular endothelial growth factor in mice. Cancer Res 66: 10315-10324, 2006.

8. Kalinsky K, Mayer JA, Xu X, Pham T, Wong KL, Villarin E, Pircher TJ, Brown M, Maurer MA and Bischoff FZ: Correlation of hormone receptor status between circulating tumor cells, primary tumor, and metastasis in breast cancer patients. Clin Transl Oncol 17: 539-546, 2015.

9. Valastyan S and Weinberg RA: Tumor metastasis: Molecular insights and evolving paradigms. Cell 147: 275-292, 2011.

10. Srikrishna G: S100A8 and S100A9: New insights into their roles in malignancy. J Innate Immun 4: 31-40, 2012.

11. Leukert N, Vogl T, Strupat K, Reichelt R, Sorg C and Roth J: Calcium-dependent tetramer formation of S100A8 and S100A9 is essential for biological activity. J Mol Biol 359: 961-972, 2006.

12. Lim SY, Raftery MJ and Geczy CL: Oxidative modifications of DAMPs suppress inflammation: The case for S100A8 and S100A9. Antioxid Redox Signal 15: 2235-2248, 2011.

13. Porta C,Larghi P,Rimoldi M, Totaro MG, Allavena P,Mantovani A and Sica A: Cellular and molecular pathways linking inflammation and cancer. Immunobiology 214: 761-777, 2009.

14. Hiratsuka S, Watanabe A, Sakurai Y, Akashi-Takamura S, Ishibashi S, Miyake K, Shibuya M, Akira S, Aburatani H and Maru Y: The S100A8-serum amyloid A3-TLR4 paracrine cascade establishes a pre-metastatic phase. Nat Cell Biol 10: $1349-1355,2008$

15. Kapanadze T, Gamrekelashvili J, Ma C, Chan C, Zhao F, Hewitt S, Zender L, Kapoor V, Felsher DW, Manns MP, et al: Regulation of accumulation and function of myeloid derived suppressor cells in different murine models of hepatocellular carcinoma. J Hepatol 59: 1007-1013, 2013.

16. Hamerlik P, Lathia JD, Rasmussen R, Wu Q, Bartkova J, Lee M, Moudry P, Bartek J Jr, Fischer W, Lukas J, et al: Autocrine VEGF-VEGFR2-Neuropilin-1 signaling promotes glioma stem-like cell viability and tumor growth. J Exp Med 209: 507-520, 2012.

17. Chatterjee S, Heukamp LC, Siobal M, Schöttle J, Wieczorek C, Peifer M, Frasca D, Koker M, König K, Meder L, et al: Tumor VEGF:VEGFR2 autocrine feed-forward loop triggers angiogenesis in lung cancer. J Clin Invest 123: 1732-1740, 2013.

18. Alessi C, Scapulatempo Neto C, Viana CR and Vazquez VL: PD-1/PD-L1 and VEGF-A/VEGF-C expression in lymph node microenvironment and association with melanoma metastasis and survival. Melanoma Res 27: 565-572, 2017.

19. Yang X, Zhang Y, Hosaka K, Andersson P, Wang J, Tholander F, Cao Z, Morikawa H, Tegnér J, Yang Y, et al: VEGF-B promotes cancer metastasis through a VEGF-A-independent mechanism and serves as a marker of poor prognosis for cancer patients. Proc Natl Acad Sci USA 112: E2900-E2909, 2015.

20. Gay LJ and Felding-Habermann B: Contribution of platelets to tumour metastasis. Nat Rev Cancer 11: 123-134, 2011.

21. Dehghani S, Nosrati R, Yousefi M, Nezami A, Soltani F, Taghdisi SM, Abnous K, Alibolandi M and Ramezani M: Aptamer-based biosensors and nanosensors for the detection of vascular endothelial growth factor (VEGF): A review. Biosens Bioelectron 110: 23-37, 2018. 
22. Huang D, Song SJ, Wu ZZ, Wu W, Cui XY, Chen JN, Zeng MS and Su SC: Epstein-barr virus-induced VEGF and GM-CSF drive nasopharyngeal carcinoma metastasis via recruitment and activation of macrophages. Cancer Res 77: 3591-3604, 2017.

23. Zhang Z, Ji S, Zhang B, Liu J, Qin Y, Xu J and Yu X: Role of angiogenesis in pancreatic cancer biology and therapy. Biomed Pharmacother 108: 1135-1140, 2018.

24. Van Dreden P, Epsilonlalamy I and Gerotziafas GT: The role of tissue factor in cancer-related hypercoagulability, tumor growth, angiogenesis and metastasis and future therapeutic strategies. Crit Rev Oncog 22: 219-248, 2017.

25. Long T, Liu Z, Shang J, Zhou X, Yu S, Tian H and Bao Y: Polygonatum sibiricum polysaccharides play anti-cancer effect through TLR4-MAPK/NF- $\kappa \mathrm{B}$ signaling pathways. Int J Biol Macromol 111: 813-821, 2018.

26. Gu JW, Young E, Busby B, Covington J and Johnson JW: Oral administration of pyrrolidine dithiocarbamate (PDTC) inhibits VEGF expression, tumor angiogenesis, and growth of breast cancer in female mice. Cancer Biol Ther 8: 514-521, 2009.

27. Gan L, Pan S, Cui J, Bai J, Jiang P and He Y: Functional analysis of the correlation between ABCB11 gene mutation and primary intrahepatic stone. Mol Med Rep 19: 195-204, 2019.

28. Pan S, Li X, Jiang P, Jiang Y, Shuai L, He Y and Li Z: Variations of ABCB4 and ABCB11 genes are associated with primary intrahepatic stones. Mol Med Rep 11: 434-446, 2015.

29. Zhang B, Wang D, Ji TF, Shi L and Yu JL: Overexpression of IncRNA ANRIL up-regulates VEGF expression and promotes angiogenesis of diabetes mellitus combined with cerebral infarction by activating NF- $\mathrm{BB}$ signaling pathway in a rat model Oncotarget 8: 17347-17359, 2017.

30. Labelle M and Hynes RO: The initial hours of metastasis: The importance of cooperative host-tumor cell interactions during hematogenous dissemination. Cancer Discov 2: 1091-1099, 2012.

31. Shin JM, Park JH, Kim HJ, Park IH and Lee HM: Cigarette smoke extract increases vascular endothelial growth factor production via TLR4/ROS/MAPKs/NF-kappaB pathway in nasal fibroblast. Am J Rhinol Allergy 31: 78-84, 2017.

32. Naruishi $\mathrm{K}$ and Nagata T: Biological effects of interleukin-6 on Gingival Fibroblasts: Cytokine regulation in periodontitis. J Cel Physiol 233: 6393-6400, 2018.

33. Sonbare DJ: Influence of surgical margins on outcome in patients with intrahepatic cholangiocarcinoma: A multicenter study by the AFC-IHCC-2009 Study Group. Ann Surg 259: e36, 2014

34. Lau SH and Lau WY: Current therapy of hilar cholangiocarcinoma. Hepatobiliary Pancreat Dis Int 11: 12-17, 2012.

35. Yin DL, Liang YJ, Zheng TS, Song RP, Wang JB, Sun BS, Pan SH, Qu LD, Liu JR, Jiang HC and Liu LX: EF24 inhibits tumor growth and metastasis via suppressing NF-kappaB dependent pathways in human cholangiocarcinoma. Sci Rep 6: 32167, 2016.

36. Ghavami S, Rashedi I, Dattilo BM, Eshraghi M, Chazin WJ, Hashemi M, Wesselborg S, Kerkhoff C and Los M: S100A8/A9 at low concentration promotes tumor cell growth via RAGE ligation and MAP kinase-dependent pathway. J Leukoc Biol 83: 1484-1492, 2008.

37. Shabani F, Farasat A, Mahdavi M and Gheibi N: Calprotectin (S100A8/S100A9): A key protein between inflammation and cancer. Inflamm Res 67: 801-812, 2018.

38. Miller P, Kidwell KM, Thomas D, Sabel M, Rae JM, Hayes DF, Hudson BI, El-Ashry D and Lippman ME: Elevated S100A8 protein expression in breast cancer cells and breast tumor stroma is prognostic of poor disease outcome. Breast Cancer Res Treat 166: 85-94, 2017.
39. Steinckwich N, Schenten V, Melchior C, Bréchard S and Tschirhart EJ: An essential role of STIM1, Orai1, and S100A8-A9 proteins for $\mathrm{Ca} 2+$ signaling and FcgammaR-mediated phagosomal oxidative activity. J Immunol 186: 2182-2191, 2011.

40. Ieguchi K, Omori T, Komatsu A, Tomita T, Deguchi A and Maru Y: Ephrin-A1 expression induced by S100A8 is mediated by the toll-like receptor 4. Biochem Biophys Res Commun 440: 623-629, 2013.

41. Tanriover G, Eyinc MB, Aliyev E, Dilmac S and Erin N: Presence of S100A8/Gr1-positive myeloid-derived suppressor cells in primary tumors and visceral organs invaded by breast carcinoma cells. Clin Breast Cancer 18: e1067-e1076, 2018.

42. Weis SM and Cheresh DA: Tumor angiogenesis: Molecular pathways and therapeutic targets. Nat Med 17: 1359-1370, 2011.

43. Gacche RN and Meshram RJ: Angiogenic factors as potential drug target: Efficacy and limitations of anti-angiogenic therapy. Biochim Biophys Acta 1846: 161-179, 2014.

44. Viallard C and Larrivée B: Tumor angiogenesis and vascular normalization: Alternative therapeutic targets. Angiogenesis 20: 409-426, 2017

45. Liang W and Ferrara N: The Complex role of neutrophils in tumor angiogenesis and metastasis. Cancer Immunol Res 4: 83-91, 2016.

46. Li C, Li S, Jia C, Yang L, Song Z and Wang Y: Low concentration of S100A8/9 promotes angiogenesis-related activity of vascular endothelial cells: Bridges among inflammation, angiogenesis, and tumorigenesis? Mediators Inflamm 2012: 248574, 2012

47. Viemann D, Strey A, Janning A, Jurk K, Klimmek K, Vogl T, Hirono K, Ichida F, Foell D, Kehrel B, et al: Myeloid-related proteins 8 and 14 induce a specific inflammatory response in human microvascular endothelial cells. Blood 105: 2955-2962, 2005.

48. Viemann D, Barczyk K, Vogl T, Fischer U, Sunderkötter C, Schulze-Osthoff K and Roth J: MRP8/MRP14 impairs endothelial integrity and induces a caspase-dependent and -independent cell death program. Blood 109: 2453-2460, 2007.

49. Li Y, Xie G, Li L, Jiang Z, Yue Z and Pan Z: The effect of TLR4/MyD88/NF-kB signaling pathway on proliferation and apoptosis in human nasopharyngeal carcinoma 5-8F cells induced by LPS. Lin Chuang Er Bi Yan Hou Tou Jing Wai Ke Za Zhi 29: 1012-1015, 2015 (In Chinese).

50. Jiang N, Xie F, Guo Q, Li MQ, Xiao J and Sui L: Toll-like receptor 4 promotes proliferation and apoptosis resistance in human papillomavirus-related cervical cancer cells through the Toll-like receptor 4/nuclear factor- $\kappa \mathrm{B}$ pathway. Tumour Biol 39: 1010428317710586, 2017

51. O'Driscoll CM, Lima MP, Kaufmann WE and Bressler JP: Methyl $\mathrm{CpG}$ binding protein 2 deficiency enhances expression of inflammatory cytokines by sustaining NF- $\kappa \mathrm{B}$ signaling in myeloid derived cells. J Neuroimmunol 283: 23-29, 2015.

52. Low P, Clark AM, Chou TC, Chang TC, Reynolds M and Ralph SJ: Immunomodulatory activity of Melaleuca alternifolia concentrate (MAC): Inhibition of LPS-induced NF- $\kappa$ B activation and cytokine production in myeloid cell lines. Int Immunopharmacol 26: 257-264, 2015.

This work is licensed under a Creative Commons Attribution-NonCommercial-NoDerivatives 4.0 International (CC BY-NC-ND 4.0) License. 